\title{
SABERES PROPOSTOS EM MANUAIS DE PREPARAÇÃO AOS EXAMES DE ADMISSÃO: O CASO DA ADMISSÃO AO GINÁSIO ${ }^{1}$
}

\author{
Késia Caroline Ramires Neves \\ Universidade Federal de Mato Grosso do Sul \\ kesiaramires@hotmail.com
}

\begin{abstract}
RESUMO
A discussão deste trabalho está pautada em indícios encontrados no manual preparatório para os exames de admissão ao ginásio, o Admissão ao Ginásio, uma produção de 1953 de autoras do Rio Grande do Sul. A investigação procurou identificar elementos que informassem sobre os saberes escolares exigidos nas provas e sobre os saberes voltados aos professores para ensinar a matemática dos exames. Ao abordar essa questão, o trabalho retratou a intenção das autoras em não somente preparar os alunos para a realização dos exames, mas também de informá-los sobre os aspectos culturais, sociais e de crescimento econômico do país, bem como nortear o ensino dos professores, também manuseadores do manual, com subsídios que fossem além dos saberes disciplinares. Assim, foram identificados alguns tipos de recursos para ensinar aquilo que seria exigido nas provas dos exames, foram verificados quais saberes foram priorizados para o ingresso no ensino secundário, como também foi observada a importância com que as autoras tratavam alguns desses saberes para abordar os problemas sugeridos ao fim das seções do livro. Portanto, esperamos que o trabalho possa colaborar com a história da educação sul-rio-grandense e ainda com a história da educação matemática do Brasil.
\end{abstract}

Palavras-chave: Manuais preparatórios. Exames de admissão ao ginásio. Saberes escolares. Saberes docentes. História da matemática escolar.

\section{KNOWLEDGE PROPOSED IN MANUALS OF PREPARATION FOR EXAMINATIONS OF ADMISSION: THE CASE OF ADMISSION TO GYMNASIUM}

\begin{abstract}
This work is based on evidences found in the preparatory textbook for admission tests to the gymnasium by children, named as Admission to Gymnasium, elaborated in 1953 by authors from the state of Rio Grande do Sul. Their research summarized a set of fundamentals and skills required to the tests, as well as the knowledge and competencies needed for educators to teach the math of the exams. In this context, this paper addresses the idea of the authors of not only to prepare students for the exams, but also to work effectively with them from different backgrounds, such as cultural and socioeconomic. In addition, a discussion of foundational knowledge and competencies needed for high-quality practice for education among professionals is described. In order to achieve this goal, we identified some resources for learning experiences required during the exam tests, skills for admission to secondary education, as well as the importance of some competencies that the
\end{abstract}

\footnotetext{
${ }^{1}$ Uma versão deste texto foi comunicado durante o Encontro Nacional em Educação Matemática, 2019.
} 
authors addressed for the resolution of mathematical problems suggested at the end-sections of the book. Therefore, this work can support educational practices and to collaborate closely related with the history of Rio Grande do Sul as well as with the history of higher quality mathematical education in Brazil.

Key-words: Preparatory manuals. Exams for admission to the gymnasium. School knowledge. Teacher knowledge. History of school mathematics.

\section{CONNAISSANCES PROPOSEES DANS LES MANUELS DE PREPARATION AUX EXAMENS D'ADMISSION: LE CAS DE L'ADMISSION AU GYMNASE}

\section{RÉSUMÉ}

Ce travail est basé sur des preuves trouvées dans le manuel préparatoire aux tests d'admission au gymnase par des enfants, nommé Admission au Gymnase, élaboré en 1953 par des auteurs de l'État du Rio Grande do Sul. Leurs recherches ont compilé un ensemble de principes fondamentaux et de compétences nécessaires aux tests, ainsi que les connaissances et les compétences nécessaires aux enseignants pour enseigner les mathématiques aux examens. Dans ce contexte, cet article aborde l'idée des auteurs de non seulement de préparer les étudiants aux examens, mais également de travailler efficacement avec eux provenant d'horizons différents, tels que culturel et socioéconomique. En outre, une discussion sur les connaissances fondamentales et les compétences nécessaires pour une pratique de haute qualité en matière d'éducation est décrite. Afin d'atteindre cet objectif, nous avons identifié quelques ressources pour les expériences d'apprentissage requises lors des examens, les compétences pour l'admission dans l'enseignement secondaire, ainsi que l'importance de certaines compétences que les auteurs ont abordées pour la résolution des problèmes mathématiques suggérés à la fin des sections du livre. Par conséquent, ce travail peut soutenir des pratiques éducatives et collaborer étroitement lié à l'histoire de Rio Grande do Sul ainsi qu'à l'histoire de l'enseignement mathématique de qualité supérieure au Brésil.

Mots-clés: Manuels de préparation. Tests d'admission au gymnase. Connaissances scolaires. Connaissance de l'enseignant. Histoire des mathématiques scolaires.

\section{SABERES PROPUESTOS EN MANUALES DE PREPARACION A LOS EXAMENES DE ADMISION: EL CASO DE LA ADMISION AL GIMNASIO}

\section{RESUMEN}

Este trabajo se basa en las evidencias encontradas en el manual preparatorio para las pruebas de admisión al gimnasio para niños, denominado Admisión al Gimnasio, elaborado en 1953 por autores de Rio Grande do Sul. Su investigación recopiló un conjunto de fundamentos y habilidades requeridas para los exámenes, así como los conocimientos y competencias necesarios para que los educadores enseñen las matemáticas de los exámenes. En este contexto, este documento aborda la idea de los autores no solo de preparar a los estudiantes para los exámenes, sino también de trabajar eficazmente con ellos desde diferentes aspectos, como el cultural y el socioeconómico. Además, se describe una discusión del conocimiento fundamental y las competencias necesarias para una práctica de alta calidad para la educación entre profesionales. Para lograr este objetivo, 
identificamos algunos recursos para las experiencias de aprendizaje requeridas durante los exámenes, las habilidades de admisión a la educación secundaria, así como la importancia de algunas competencias que los autores abordaron para la resolución de problemas matemáticos sugeridos al final del libro. Por lo tanto, este trabajo puede respaldar las prácticas educativas y colaborar estrechamente en relación con la historia de Rio Grande do Sul, así como con la historia de la educación matemática de mayor calidad en Brasil.

Palabras-clave: Manuales preparatorios. Exámenes de admisión al gimnasio. Saberes escolares. Conocimientos y competencias de los educadores. Historia de la matemática escolar.

\section{INTRODUÇÃO}

Os exames de admissão ao ginásio ainda são tema fecundo para os pesquisadores em história da educação. Dentre esses, uma boa parcela dedicou-se ao assunto debruçando-se sobre a forma didática das questões dos exames, sobre a tipologia e estrutura das provas, inventariou os programas que normatizavam os exames, analisou e discutiu sobre os conteúdos ${ }^{2}$ que eram exigidos (MACHADO, 2002; AKSENEN, 2013; AKSENEN; MIGUEL, 2012; SANTOS, 2017; PESSANHA; DANIEL, 2002). No entanto, ainda são incipientes os estudos interessados em compreender sobre esses exames a partir dos manuais ${ }^{3}$ preparatórios e o que esses manuais podem nos dizer sobre o ensino dos saberes escolares - problemática, essa, que os historiadores em educação matemática podem examinar.

Particularmente, o longo período em que estiveram vigentes os exames de admissão ao ginásio (1930 a 1970) mostra-nos o quão importante foi essa política avaliativa para o país, sendo um projeto de seleção de alunos para ingresso no ensino secundário, mas também uma política que afetou, em certa medida, o ensino primário e secundário. É sabido que o primário teve um ano a mais de estudos para os jovens que prestariam as provas, promovendo um curso preparatório para os exames. E o secundário, embora tivesse menos vagas do que alunos, chegou a preocupar com a alta taxa de reprovados nos exames e o baixo número de ingressantes nesse nível de ensino. Assim, ainda há discussões a serem feitas sobre a relação e os efeitos que essa política causou à educação básica de nosso país.

\footnotetext{
${ }^{2}$ Neste trabalho, não será nossa intenção distinguir as palavras seguintes por seus significados; teremos o mesmo entendimento sobre todas elas, qual seja, de que se tratam de saberes escolares, aqueles ensinados na escola, das disciplinas. As palavras que trataremos como sinônimas serão: saberes, conteúdos, assuntos, conceitos.

${ }^{3}$ Embora Choppin (2002) faça uma distinção entre livros didáticos e manuais pedagógicos - o primeiro, por ser voltado aos alunos e o segundo, aos professores - , como a obra que analisamos foi destinada aos dois públicos, neste trabalho vamos tratar livro e manual como sinônimos.
}

Rev. Iberoam. Patrim. Histórico-Educativo, Campinas (SP), v. 5, p. 1-16, e019031, 2019. 
Mas, para além de uma discussão sociológica e política sobre o efeito dos exames na educação brasileira, também há campo para discussão dentro da educação matemática, como já comentamos. Vejamos que, em uma busca realizada recentemente em plataformas digitais com a palavra-chave admissão, e ao ler o escopo dos trabalhos para verificar se discutiam sobre a admissão ao ginásio, localizamos 1 artigo na Revista Brasileira de História da Educação, 7 comunicações entre aquelas publicadas nas 9 edições dos Congressos Brasileiros de História da Educação, 3 entre 1373 trabalhos cadastrados na BDTD - Biblioteca Digital Brasileira de Teses e Dissertações (com a palavra-chave "admissão ao ginásio") - e 4 do Banco de Teses e Dissertações da CAPES (sendo 2 iguais aos encontrados na BDTD). No Congresso Nacional de Avaliação em Educação (CONAVE), por exemplo, não há linha de pesquisa correspondente às avaliações que fizeram parte do processo histórico escolar, logo, não há discussões sobre os exames de admissão. Na revista Estudos em Avaliação Educacional, há 1 trabalho que aborda as avaliações de promoção ao ginásio, mas são aquelas do período letivo normal, não sendo, portanto, as dos exames de admissão. No I Seminário Paulista de História e Educação Matemática, também encontramos somente 1 comunicação. Deste modo, verificamos um resultado bastante baixo de trabalhos publicados e disponibilizados nas plataformas digitais.

Além dessa busca, em evento realizado em Boa Vista (RR), o XVI Seminário Temático: provas, exames e a escrita da história da educação matemática, 60 trabalhos foram apresentados. Dentre eles, apenas o de Ivone Lemos da Rocha (Problemas aritméticos e suas resoluções algébricas - um breve estudo em manuais pedagógicos, 1890-1940) e o de Mariliza Simonete Portela e Antonio Flavio Claras (Provas e exames de admissão no estado do Paraná 1961: orientações oficiais versus a apropriação pela Escola) destacaram, no título, uma abordagem aos exames de admissão ao ginásio por meio dos manuais preparatórios e/ou pedagógicos, abordagem essa que se assemelha a que pretendemos neste artigo. A maioria dos outros trabalhos tratou dos exames de admissão ao ginásio utilizando programas oficiais e/ou provas como fontes de pesquisa ou foram trabalhos que discutiram os exames de admissão de ingresso para a Escola Normal. Nesse sentido, nosso levantamento chama atenção à lacuna existente de pesquisas histórico-educacionais voltadas aos manuais preparatórios para os exames de admissão ao ginásio, e chama atenção também a lacunas quanto ao tipo de estrutura didática ou abordagem para o ensino dos saberes escolares e sobre os tipos de problemas e exercícios que eram priorizados nesse contexto e nesses manuais. 
Assim, pesquisar manuais preparatórios aos exames de admissão ao ginásio pode nos levar a obter informações sobre um currículo escolar, pois tais materiais, em vários casos, subsidiaram o trabalho docente e nortearam o estudo dos alunos (GOMES, 2013), como foi o manual que analisamos. Mais especificamente, esse tipo de material pode apresentar particularidades quanto à leitura que o país fazia para a formação de seus jovens, como também pode apontar-nos os saberes necessários que professores deveriam conhecer para preparar os alunos para as provas dos exames. Seguindo a linha de Choppin (2002, p. 16), os manuais seriam então uma referência que permitiria ao "historiador reconstituir os canais de propagação das ideias e as vias de circulação dos capitais".

A princípio, quando se pensa em manuais para professores, tem-se em mente a veiculação de ideais sobre os saberes disciplinares. Contudo, podemos buscar indícios que informem mais do que isso, ou seja, que proponham saberes - voltados aos professores - além dos disciplinares, tais como: saberes sobre métodos, sobre didática, sobre formas de ensinar ou saberes pedagógicos, saberes psicológicos, saberes sociais, saberes sobre as provas e regras da política avaliativa, etc. Dessa forma, nossa pesquisa indaga: que ideias esses manuais preparatórios para os exames de admissão ao ginásio transmitiriam quanto aos saberes escolares exigidos nas provas dos exames ou sobre aqueles voltados aos professores? O manual selecionado para a pesquisa tinha a intenção de trazer informações sobre esses saberes?

Portanto, analisamos o Admissão ao Ginásio tendo em vista a perspectiva ora apresentada e entendendo que esses materiais ocuparam lugar privilegiado na época dos exames de admissão devido a: constituírem-se como meios de desvelar traços políticos, científicos, culturais, pedagógicos, de concepções, de formas de produção e de usos (CHOPPIN, 2002); serem fontes a dar-nos indicativos de uma política avaliativa e seus desdobramentos quanto à limitação e programação de conteúdos privilegiados - exigidos nas provas dos exames - , bem como indicativos, talvez, sobre os saberes voltados à prática dos professores dos cursinhos preparatórios. A partir disso, nas próximas seções, mostraremos os resultados que obtivemos sobre os tipos de saberes constatados no livro e a intenção ou ideias incutidas na textualização do manual. Antes, porém, é preciso ressaltar qual saber matemático priorizamos na análise. Para fins de limitação deste trabalho, selecionamos analisar a fração, pois esse conceito foi o que mais ocupou espaço no Programa de Matemática do livro, o que poderia nos levar a encontrar mais características sobre o manual. 


\section{O MANUAL ADMISSÃO AO GINÁSIO}

O manual que abordamos foi publicado por três autoras que, segundo Ramil (2011, p. 4), eram "importantes nomes no campo da produção didática" do Rio Grande do Sul. A obra, denominada Admissão ao Ginásio ${ }^{4}$, tem autoria de Edith Guimarães Lima, Maria Guimarães Ribeiro e Giselda Guimarães Gomes, Título 1 do quadro seguinte - nesse quadro temos dados de alguns manuais preparatórios já encontrados.

QUADRO 1 - Manuais Preparatórios aos Exames de Admissão ao Ginásio

\begin{tabular}{|c|c|c|c|c|c|}
\hline & Título & Autor(es) & Ano & Edição & Áreas contidas \\
\hline 1 & $\begin{array}{l}\text { Admissão ao } \\
\text { ginásio }\end{array}$ & $\begin{array}{l}\text { Edith Guimarães Lima } \\
\text { Maria Guimarães Ribeiro } \\
\text { Giselda Guimarães Gomes }\end{array}$ & $\approx 1953^{5}$ & 4 & $\begin{array}{c}\text { Português } \\
\text { Geografia } \\
\text { História } \\
\text { Aritmética }\end{array}$ \\
\hline 2 & $\begin{array}{l}\text { Manual de } \\
\text { admissão }\end{array}$ & $\begin{array}{l}\text { Cecil Thiré } \\
\text { Catedrático de Matemática } \\
\text { do Colégio Pedro II } \\
\text { J. B. Mello e Souza } \\
\text { Catedrático de História da } \\
\text { Civilização do Colégio } \\
\text { Pedro II }\end{array}$ & 1942 & 4 & $\begin{array}{c}\text { Português } \\
\text { Aritmética } \\
\text { Geografia } \\
\text { Hist. do Brasil } \\
\text { Ciências }\end{array}$ \\
\hline 3 & $\begin{array}{l}\text { Exercícios de } \\
\text { aritmética para o } \\
\text { curso de admissão }\end{array}$ & $\begin{array}{l}\text { Ary Quintella } \\
\text { Newton O'Reilly }\end{array}$ & 1954 & 10 & Aritmética \\
\hline 4 & $\begin{array}{l}\text { Curso de } \\
\text { admissão ao } \\
\text { ginásio - } \\
\text { Problemas de } \\
\text { Matemática }\end{array}$ & $\begin{array}{l}\text { Antonio de Souza Teixeira } \\
\text { Jr. }\end{array}$ & 1958 & 2 & Matemática \\
\hline 5 & $\begin{array}{l}\text { Mil e uma } \\
\text { expressões } \\
\text { aritméticas para o } \\
\text { curso de admissão } \\
\text { e primeira série } \\
\text { ginasial }\end{array}$ & Newton O'Reilly & 1959 & 4 & Aritmética \\
\hline 6 & $\begin{array}{l}\text { Aritmética - } \\
\text { admissão ao curso } \\
\text { ginasial }\end{array}$ & Andréa Fontes Peixoto & 1961 & 14 & Aritmética \\
\hline 7 & Admissão ginasial & João Barbosa de Moraes & 1963 & 43 & $\begin{array}{c}\text { Português } \\
\text { Aritmética } \\
\text { Geografia } \\
\text { Hist. do Brasil }\end{array}$ \\
\hline
\end{tabular}

${ }^{4}$ Esse manual, ao que tudo indica, não foi analisado por nenhum historiador, tampouco da educação matemática, mostrando-se assim um empreendimento inédito no âmbito da história da educação, história dos livros didáticos e da história da educação matemática.

${ }^{5}$ Consta informações sobre datação na página 215 do livro.

Rev. Iberoam. Patrim. Histórico-Educativo, Campinas (SP), v. 5, p. 1-16, e019031, 2019. 


\begin{tabular}{|c|l|l|c|c|c|}
\hline 8 & $\begin{array}{l}\text { Luz do Saber } \\
\text { (Admissão ao } \\
\text { ginásio) }\end{array}$ & Cecília Torcelli Corrêa & 1967 & $\begin{array}{c}\text { Português } \\
\text { Matemática } \\
\text { Geografia } \\
\text { Hist. do Brasil }\end{array}$ \\
\hline 9 & $\begin{array}{l}\text { Programa de } \\
\text { admissão - nôvo, } \\
\text { com matemática } \\
\text { moderna }\end{array}$ & $\begin{array}{l}\text { Aroldo de Azevedo } \\
\text { Domingos Paschoal Cegalla } \\
\text { Joaquim Silva } \\
\text { Osvaldo Sangiorgi (autor da } \\
\text { parte Matemática) }\end{array}$ & 1968 & 19 & $\begin{array}{c}\text { Português } \\
\text { Matemática } \\
\text { Hist. do Brasil } \\
\text { Geografia }\end{array}$ \\
\hline
\end{tabular}

Fonte: A autora, 2018.

Trata-se de um livro de aproximadamente 1953 e exibe a disciplina de Português, Geografia, História e Aritmética, as quais eram exigidas nas provas dos exames de admissão desse período. Ele se apresenta na $4^{\mathrm{a}}$. edição e parece manter a boa vendagem que obtiveram as demais obras das autoras Edith, Maria Guimarães e Giselda - conforme relatam no prefácio do manual. Por ser uma produção de escritoras renomadas do Estado de Rio Grande do Sul, do período de 1950, todas elas da área de ensino, presumimos que foi um livro de merecido reconhecimento e uso para a época, revelando-se um rico objeto para nossa pesquisa.

Como material didático e pedagógico, de preparação aos exames de admissão ao ginásio, teoricamente foi preparado com o intuito de articular as prescrições gerais dos programas oficiais com o que vinha sendo ensinado naquele tempo, haja vista as autoras serem atuantes no ensino. Logo, quase um testemunho escrito, permanente, mais elaborado, mais detalhado e mais rico que as instruções supunham registrar (CHOPPIN, 2002).

Sem dúvida, a especificidade do manual preparatório como ferramenta de trabalho do professor e como uma fotografia de sua prática foi elemento ao qual recorremos para buscar indícios sobre os saberes docentes para preparação dos alunos para a matemática dos exames, ou seja, buscar indícios que pudessem retratar como os professores deveriam trabalhar, junto aos seus alunos, com essa matemática. Sendo assim, nosso trabalho debruçou-se às análises sobre os saberes direcionados aos professores e sobre os saberes matemáticos exigidos nas provas, lidos e compreendidos por meio do Admissão ao Ginásio, procurando, com isso, ir além das análises de metodologias ou modos de ensino, englobando também para quem, onde e quais saberes priorizar, formas de apresentar ou introduzir temas e conteúdos, assim como recomenda Maciel (2016). 


\section{DOS INDÍCIOS ENCONTRADOS}

O Admissão ao Ginásio foi material produzido por autoras que tinham como intenção aproximar as matérias de ensino a leituras que poderiam interessar aos alunos. Assim, no prefácio, indicavam poesias na parte de Português, episódios históricos na parte de História e descrição de lugares, ou regiões, em Geografia. Curioso observar que não faziam referência ao tratamento de assuntos interessantes para a abordagem da Matemática, apesar de depois trazerem fatos do contexto brasileiro nos problemas de fim de seção da matéria.

Esse despertar para o interesse do aluno supomos ter relação com a perspectiva da escola nova, visto que outros $\operatorname{livros}^{6}$ dessas autoras para o ensino primário tinham, a princípio, uma proposta pedagógica voltada à marcha escolanovista. Fernandes (2009), ao analisar o livro "Estudos Sociais e Naturais - $1^{\circ}$. ano", de autoria de Edith Guimarães Lima e Maria Guimarães Ribeiro, publicado pela Editora do Brasil, em 2a . edição no ano de 1954, constatou, no prefácio, que as autoras mantinham "elos com os princípios didáticos da Escola Nova"; que afirmavam partir

"do que é evidente, para a criança", para "leva-la, gradativamente, a desejar o conhecimento dos fatos, situação, seres, e fenômenos, etc."; do esforço de dar uma variedade à apresentação (de textos e exercícios), para despertar seu interesse; de induzi-la a realizar seus estudos de modo ativo, incentivando experiências e observações; de dar conhecimentos complementares para que pudesse aprender por dedução; e, através de exercícios, de permitir a fixação dos conhecimentos adquiridos. (FERNANDES, 2009, p. 5, grifo da autora).

Nas seções do Admissão ao Ginásio em que se exibiam os problemas matemáticos, por exemplo, há traços da marcha escolanovista. Os problemas remetem a dados "reais" de pesquisas daquela época publicadas sobre o Brasil, como as do serviço de Economia da Secretaria de Agricultura de São Paulo e do Anuário Estatístico do Brasil, pressupondo aproximar os alunos às características do país ou às características de uma cultura escolar ${ }^{7}$, tentando problematizar situações reais. Enunciavam problemas que citavam plantas nativas do Brasil, rotas comerciais de avião recém-inauguradas na época, tipo de produtos de exportação nos quais o Brasil se destacava mundialmente, ou traziam temas relacionados à cultura escolar. Também contextualizavam o sistema métrico com rotas comerciais recém-inauguradas no Brasil. Isto significa que ora os

\footnotetext{
${ }^{6}$ Ver análise de Carola e Cabral (2013) e de Batista, Galvão e Klinke (2002).

${ }^{7}$ Cultura escolar segundo Julia (2001).
} 
problemas valorizavam as riquezas brasileiras, o crescimento econômico, projetando o patriotismo e o desenvolvimento da época, ora apelavam aos costumes dos alunos que eram vividos na escola.

FIGURA 1 - Exemplar de problema envolvendo produtos de exportação brasileira (p. 214)

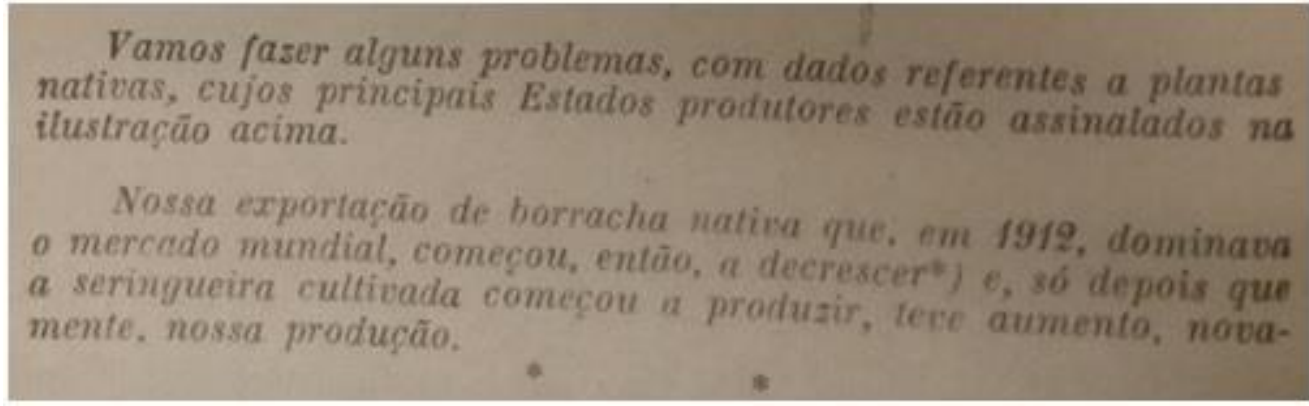

FIGURA 2 - Exemplar de problema envolvendo a cultura escolar (p. 247)

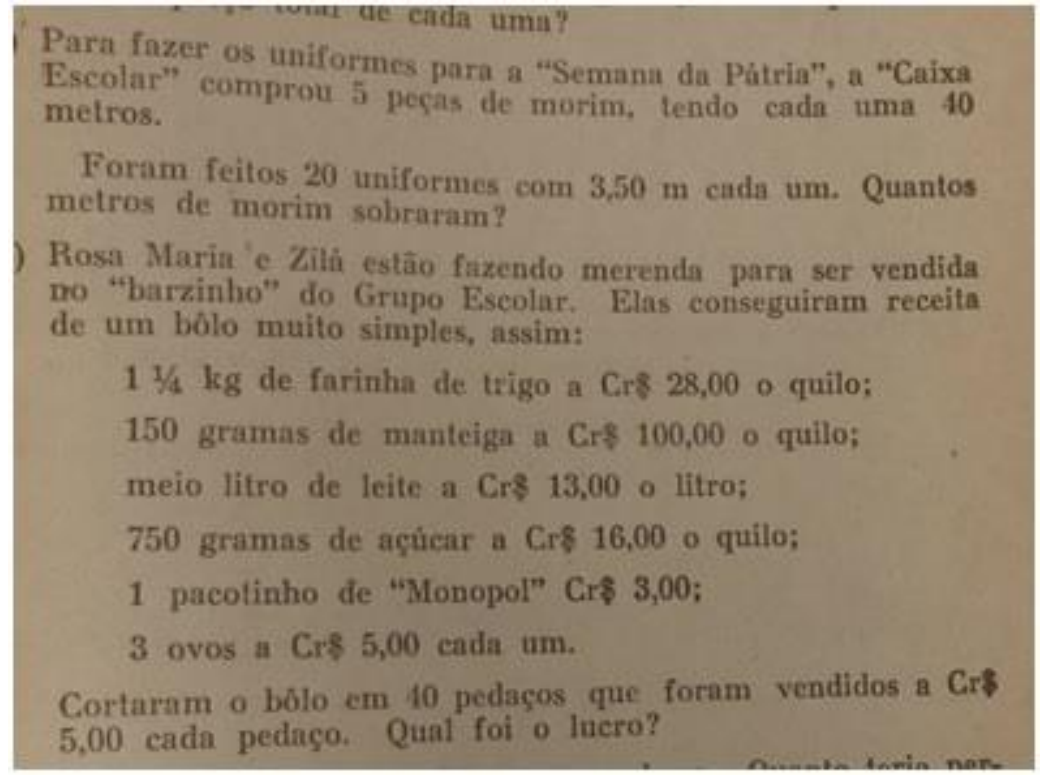

Desse modo, o manual trazia textos que, hipoteticamente, incentivavam os alunos ao gosto pela Matemática, ou que despertavam a curiosidade pelas características do Brasil, ou que induziam os alunos a explorar e observar os espaços que estudavam, permitindo-nos supor que havia resquícios da escola nova presente também no Admissão ao Ginásio.

Por esse motivo, ele se difere de alguns de seu tempo, por exemplo, o Manual de admissão, o Exercícios de aritmética para o curso de admissão e o Programa de admissão - nôvo, com matemática moderna, respectivamente o $2^{\circ}$, o $3^{\circ}$ e o $9^{\circ}$ livro do quadro 1 . Esses últimos também 
apresentavam especificidades, mas sinalizavam para uma abordagem mais técnica, trazendo muitos exercícios e problemas para exercitação das matérias, dando ênfase aos saberes disciplinares ou apenas à matemática que deveria se ensinar. Não demonstravam, portanto, tantos problemas que retratavam os aspectos culturais, ou sociais (temas como gastos de família, salário de funcionários, dívidas, etc.), ou de crescimento econômico do Brasil, assim como o Admissão ao Ginásio. Tampouco revelavam traços similares aos da escola nova, como problematizar questões de interesse dos alunos e com dispositivos didáticos para melhor se apreender os saberes escolares, tal como veremos adiante na seção dos resultados. Dessa forma, o Admissão ao Ginásio mostrounos ser um manual além do que era exigido pelos exames; pareceu-nos ser importante para a educação gaúcha, evidenciando o que se esperava dos jovens daquela época.

Adiante, apontaremos alguns resultados de nossa análise, colocando em destaque pontos da estrutura didática do livro, sobre o ensino das frações, dos dispositivos didáticos que deveriam ser utilizados e dos tipos de exercícios e problemas que compunham o manual.

\section{OS RESULTADOS CONSTATADOS}

Dividido na parte da Matemática entre resumos da matéria, seguido de exercícios e alguns problemas, o manual parecia retomar o que já tinha sido trabalhado em séries anteriores. A sequência de conteúdos matemáticos atendia ao que era prescrito no Programa de Ensino da Portaria $^{8} \mathrm{n}^{\circ}$. 501, de 19 de maio de 1952 para os exames de admissão e elencava os assuntos: Número, algarismos, unidade, grandeza. Numeração, unidades de diversas ordens. Número romano. Operações fundamentais sobre números inteiros: prova real e dos nove. Divisibilidade por 10, 5, 2, 9, 3 e 11. Números primos; decomposição de um número em fatores primos. Máximo divisor comum. Mínimo múltiplo comum. Frações ordinárias. Fração própria e imprópria; número misto. Extração de inteiros. Simplificação de frações e redução ao mesmo denominador. Comparação de frações; ordem crescente e decrescente. Números decimais. Operações sobre frações decimais. Conversão e frações decimais em ordinárias e vice-versa. Expressões fácies para aplicação das regras de conversão e de operações sobre frações decimais. Sistema métrico decimal. Metro simples, quadrado e cúbico; múltiplos e submúltiplos. Grama; múltiplos e submúltiplos. Litro; seus múltiplos e submúltiplos. Sistema monetário. Resolução de problemas fáceis sobre

\footnotetext{
${ }^{8}$ Portaria que antecede à publicação do livro.
} 
números inteiros, frações e sistema métrico decimal (Programa do Manual, 1953, p. 9). Pela observação dessa seleção de saberes escolares, é possível deduzir quais eram prioritários para ingresso no ensino secundário, ficando externado que a Geometria e a Álgebra não tinham ainda o mesmo "peso" que a Aritmética.

Ao iniciar os conteúdos do Programa de Matemática, o manual apresentava explicações rápidas ou envolvia exercícios para completar as frases sobre as "definições" que se queria transmitir. Exercícios de relacionar uma informação a outra também eram um recurso utilizado; outro, era o dispositivo didático, evidenciado em algumas partes do texto. Todos esses recursos tinham a intenção de chamar o aluno a participar das ideias matemáticas, de envolvê-lo com os conceitos que seriam trabalhados, desse modo, supostamente, esses conceitos fariam mais sentido na aprendizagem.

FIGURA 3 - Exercício sobre operações com números inteiros que pediam a relação de uma informação com outra (p. 204)

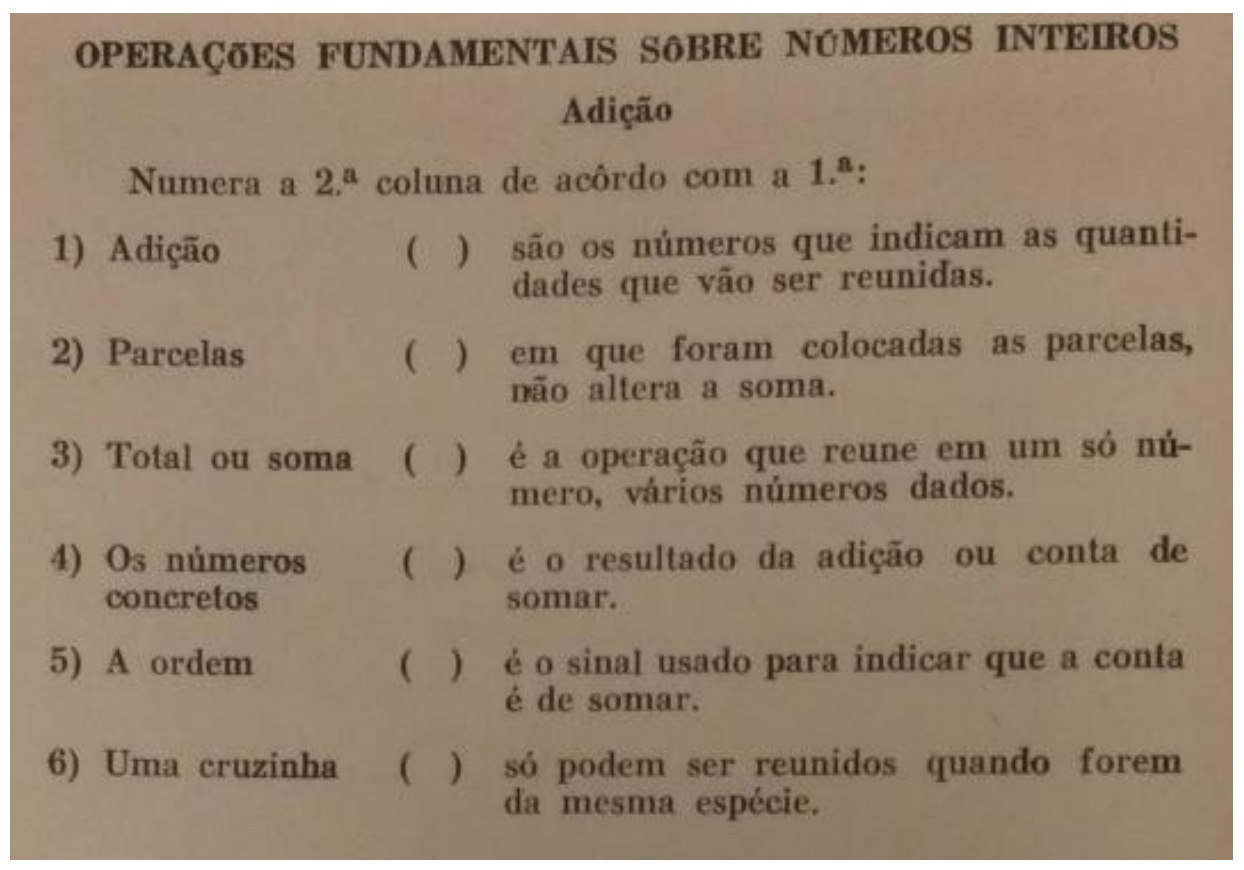


FIGURA 4 - Dispositivo didático explorado para ensinar classes de números (p. 201)

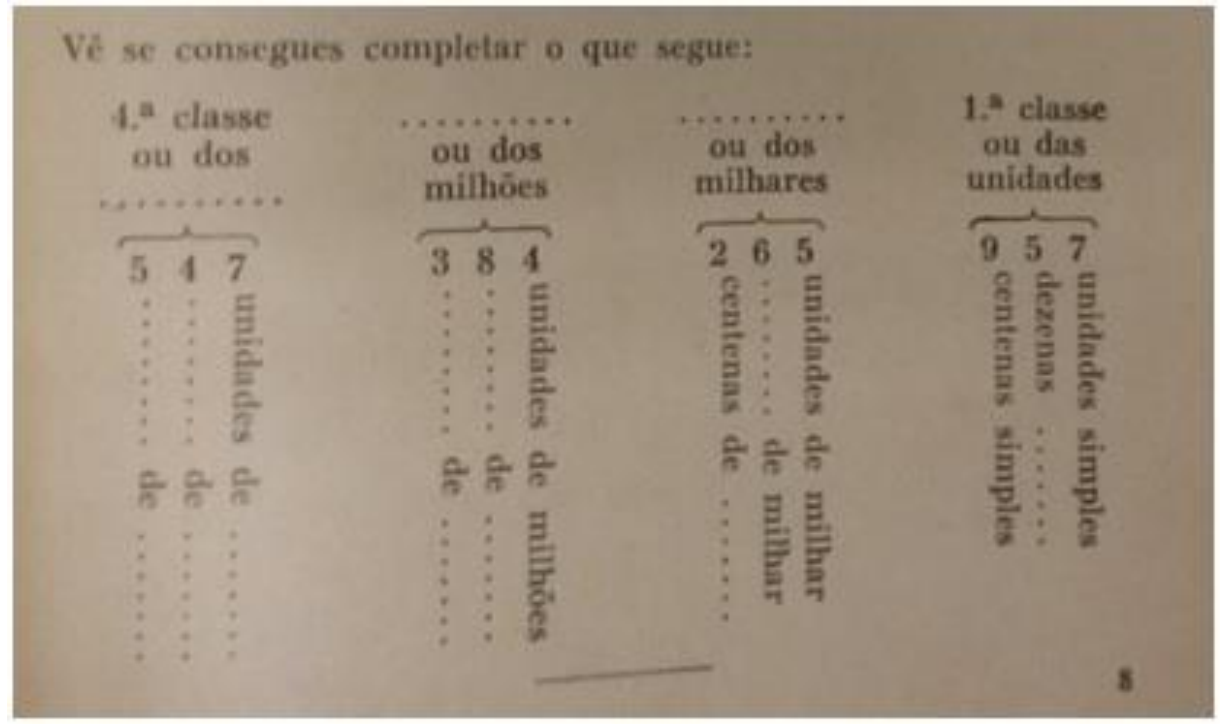

No decorrer do manual, encontravam-se muitas informações sobre dados do Brasil. Na página 204 do livro, por exemplo, há uma tabela com dados da produção de milho para trabalhar com a operação de adição de números inteiros. Após apresentação desses dados, era proposta uma sequência de exercícios, tais como: “Toma como parcelas, para fazeres uma adição, os números que indicam nossa produção de milho, dos anos de 1950 a 1954"; "Qual será a soma dos três anos de menor exportação?”, e outras questões. Na página 205, lia-se o destaque em letras maiúsculas: “O MILHO É O CEREAL MAIS CULTIVADO NO BRASIL - TODOS OS ESTADOS O CULTIVAM". No entanto, entre os saberes escolares abordados na parte Matemática, as frações, junto ao máximo e ao mínimo múltiplo comum, eram os únicos tópicos que traziam poucos problemas embasados no contexto brasileiro. Os problemas eram mais de cunho técnico, somente para exercitação das propriedades sobre os fracionários, ou, quando o caso, exercitação do máximo e mínimo múltiplo comum.

Embora, na parte sobre as frações, o foco fosse a exercitação das propriedades, destacandose "definições" de termos - numerador, denominador, número misto, fração própria e imprópria e muitos exercícios, o manual trabalhava com diferentes significados sobre esse conceito matemático, quais sejam: o de parte - todo, o de número, o de quociente e o de operador 
multiplicativo ${ }^{9}$ - ainda que naquele tempo esses significados não fossem classificados dessa forma. E antes da introdução desse conteúdo, na página 212, era apresentado um exercício que antecedia a ideia de frações equivalentes: Completa as igualdades: $50: 10=100$ : $: 9=30: 10$; $84:{ }_{1}=72: 6$ (p. 211). Esse modelo de exercício, portanto, já introduzia à ideia de fração como quociente.

FIGURA 5 - Problemas com significado de fração parte-todo (p. 227)

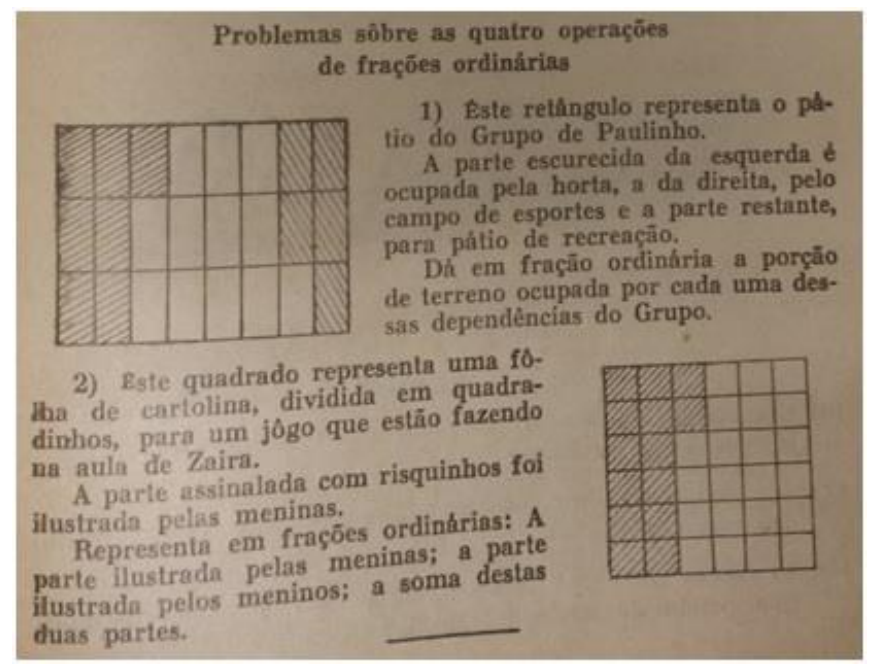

FIGURA 6 - Problemas com significado de fração como operador multiplicativo (p. 228)

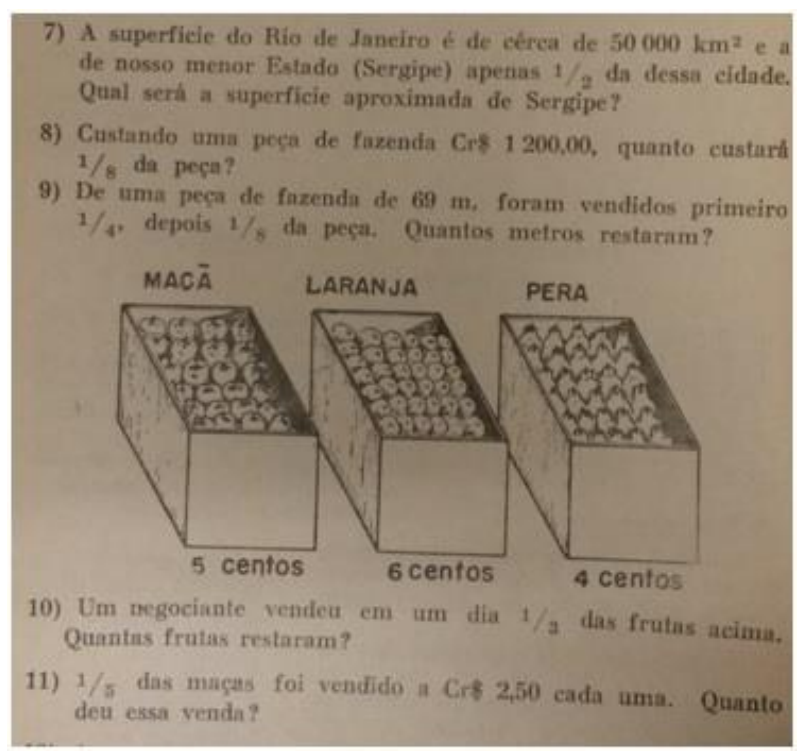

\footnotetext{
${ }^{9}$ Somente em estudos recentes Thomas E. Kieren (1980) faz uma distinção mais acentuada sobre os constructos inerentes à fração. No Brasil, Campos, Magina e Nunes (2006) e Magina e Campos (2008), discutiram sobre esses constructos também.
} 
Então, sobre a abordagem desse conceito, basicamente as autoras se concentraram na fração com significado parte-todo, apesar de apresentarem elementos que denunciavam o trabalho com os outros significados. Isso posto, podemos suspeitar que havia a intenção de fazer com que o aluno compreendesse o conceito de fração de forma mais ampla.

\section{CONSIDERAÇÕES FINAIS}

Nossa pesquisa buscou identificar ideias que manuais preparatórios para os exames de admissão ao ginásio poderiam transmitir quanto aos saberes escolares exigidos nas provas dos exames ou sobre aqueles voltados aos professores para ensinar uma matemática dos exames. Especificamente, lançamos essa investigação ao manual Admissão ao Ginásio, escrito por três autoras reconhecidas do Estado de Rio Grande do Sul, todas da área de ensino e contemporâneas do período em que os exames eram aplicados. Para fins de limitação textual, escolhemos tratar dos saberes relacionados à fração, por ser esse conceito o que mais ocupou as páginas do Programa de Matemática do livro, o que nos pareceu render mais indícios para nossa pesquisa.

Contudo, não obtivemos dados explícitos sobre as duas coisas. Quanto aos saberes matemáticos exigidos nas provas, o manual estava de acordo ao que era ensinado na época e ao que era prescrito para se avaliar nos exames. Nesse sentido, concentrava-se na Aritmética dos números inteiros, fracionários e decimais, em definições, muitos exercícios e alguns problemas para abordagem dos conceitos ensinados. Já sobre os saberes docentes (aqueles voltados ao ofício de ensinar), o livro trazia uma tímida amostra do que pretendia. Ele sugeria, implicitamente, o ensino pela marcha escolanovista, visando levar o aluno a participar das atividades propostas no livro, bem como tencionava tratar de temas supostamente do interesse dos alunos. Assim, era sugestionado aos professores que trabalhassem questões sobre o crescimento econômico do país, ilustrando novas rotas aéreas, exportação de grãos, aumento populacional, elementos da cultura ou do espaço escolar, etc., ficando subtendido que deveriam tratar desses contextos, mobilizando-os durante sua prática de ensino e manejo com o manual. Ao que tudo indica, era esperado que o professor conhecesse um pouco das questões sociais e econômicas do país ou procurasse conhecer para ensinar.

Portanto, a análise realizada sobre a obra Admissão ao Ginásio apresentou elementos que nos mostraram não somente o que pretendiam as autoras sul-rio-grandenses. A análise propôs uma 
reflexão quanto ao ensino não ser orientado apenas à preparação para os exames, mas também a olhar a formação dos alunos e aos aspectos culturais, de crescimento econômico do país e sobre a própria cultura escolar. Se as autoras tinham essa intenção quando da produção dessa obra? Não temos a certeza disso, porém, a colaboração que trouxeram pode nos orientar sobre a história da educação matemática e como ela colabora em reflexões atuais.

\section{REFERÊNCIAS}

AKSENEN, E. Z. Os exames de admissão ao ginásio, seu significado e função na educação paranaense: análise dos conteúdos matemáticos (1930 a 1971). Curitiba - PR: Pontifícia Universidade Católica do Paraná, 2013. Dissertação (Mestrado em Educação). Programa de PósGraduação em Educação, Pontifícia Universidade Católica do Paraná, 2013.

AKSENEN, E. Z.; MIGUEL, M. E. B. Um estudo da cultura escolar presente nos exames de admissão ao ginásio com ênfase na disciplina de matemática. In: IX ANPED Sul e Seminário de Pesquisa em Educação da Região Sul, 2012, Caxias do Sul/RS. Anais... do IX ANPED Sul e Seminário de Pesquisa em Educação da Região Sul. Caxias do Sul/RS: Editora Universitária de Caxias do Sul, 2012, v. 1.

BATISTA, A. A. G.; GALVÃO, A. M. O.; KLINKE, K. Livros escolares de leitura: uma morfologia (1866-1956). Revista Brasileira de Educação [online]. n. 20, pp.27-47, 2002.

BRASIL. Portaria no. 501, de 19 de maio de 1952 e legislação complementar (atualizado até março de 1960). Suplemento da Revista Atualidades Pedagógicas. Editora Companhia Editora Nacional. 183 páginas. Documento encontrado no Centro de Memória do Colégio Estadual do Paraná.

CAMPOS, T. M. M.; MAGINA, S.; NUNES, T. O professor polivalente e a fração: conceitos e estratégias de ensino. Educação Matemática Pesquisa, São Paulo (SP), v. 8, n. 1, p. 125-136, 2006.

CAROLA, C. R.; CABRAL, G. S. Concepções de natureza e sensibilidade ambiental nos livros didáticos de História Natural (1934-1971). Revista Brasileira de Estudos Pedagógicos. (online), Brasília, v. 94, n. 238, p. 858-880, set./dez. 2013.

CHOPPIN, A. O historiador e o livro escolar. História da Educação. ASPHE/FaE/UFPel, Pelotas (11): 5-24, Abr. 2002.

FERNANDES, A. T.C. Livros didáticos e a integração da vida social e natural. In: XXV Simpósio Nacional de História - História e Ética, 2009, Fortaleza/CE. Anais... do XXV Simpósio Nacional de História - História e Ética, Fortaleza/CE: Editora Universitária da Universidade Federal do Ceará, 2009. 
GOMES, M. L. M. História do Ensino da Matemática: uma introdução. Belo Horizonte:

CAED - UFMG, 2013.

JULIA, D. A cultura escolar como objeto histórico. Revista Brasileira de História da Educação, Campinas, n. 1, p. 9 - 43, jan/ jun. 2001.

KIEREN, T. E. Personal Knowledge of rational numbers: its intutive and formal development .In: Hiebert, J and Behr, M. ( eds.) Number Concepts and Operations in the Middle Grades. Hillsdale, New Jersey: Erlbaum, p. 162-180, 1980.

LIMA, E. G.; RIBEIRO, M. G.; GOMES, G. G. Admissão ao Ginásio. 4 ed., Rio Grande do Sul: Livraria Selbach, 1953.

MACHADO, R. de C. G. Uma análise dos exames de admissão ao secundário (1930-1970): subsídios para a história da educação matemática. (2002) Dissertação (Mestrado em Educação Matemática). PUC - SP, São Paulo - SP.

MACIEL, V. B. Caracterizando saberes para ensinar arithmética no curso primário em manuais pedagógicos. Caminhos da Educação Matemática em Revista (on line), Sergipe, v. 6, n. 1, p. 45-56, 2016.

MAGINA, S.; CAMPOS, T. M. M. A Fração nas Perspectivas do Professor e do Aluno dos Dois Primeiros Ciclos do Ensino Fundamental. Bolema, Rio Claro (SP), ano 21, n. 31, p. 23-40, 2008.

PESSANHA, E. C.; DANIEL, M. E. B. História da Cultura Escolar Através dos Exames: o Caso dos Exames de Admissão ao Ginásio (1939-1971). Intermeio, Campo Grande, MS, v. 8, n. 16, p. 4-15, 2002.

RAMIL, C. A. A produção da coleção de livros didáticos "tapete verde" na década de 70: considerações iniciais de pesquisa. In: $17^{\circ}$ Encontro da Associação Sul-Rio-Grandense de Pesquisadores em História da Educação, 2011, Santa Maria/RS. Anais... do $17^{\circ}$ Encontro da Associação Sul-Rio-Grandense de Pesquisadores em História da Educação, Santa Maria/RS: Editora Universitária da Universidade Federal de Santa Maria, 2011.

SANTOS, R. Saberes matemáticos identificados em provas do exame de admissão ao ginásio do Colégio São Paulo (1931-1969). Dissertação (Mestrado em Ensino de Ciências e Matemática), Universidade Federal de Sergipe, São Cristóvão (SE), 2017.

Recebido em: 22 de maio de 2019 Aceito em: 14 de dezembro de 2019 